\title{
Zig-Zag y la irrupción editorial: La ciudad letrada "zigzagueante"*
}

\author{
Marina d.A. Alvarado Cornejo**
}

\section{Resumen}

El objetivo de este trabajo es reconocer la importancia de la irrupción de la editorial Zig- Zag y su magazín homónimo en el proceso de legitimación y expansión de la producción literaria chilena durante las primeras dos décadas del siglo XX. Para esto, identificamos las estrategias desplegadas por la publicación semanal, las que analizamos a la luz de la noción "ciudad letrada" de Ángel Rama.

Palabras clave: Editorial Zig-Zag, magazín Zig-Zag, legitimación de la producción literaria, "ciudad letrada".

\section{Zig-Zag and the publishing emergence: The zigzagueante ciudad letrada}

\begin{abstract}
The aim of this paper is to recognize the importance of the emergence of Zig-Zag Publisher and its magazine with the same name, in the process of legitimation and expansion of the Chilean literary production during the first two decades of the twentieth century. For this purpose, we identify the strategies employed by the weekly publication, which are analyzed in light of the reappropriation of the notion of ciudad letrada by Angel Rama.
\end{abstract}

Key words: Zig-Zag Publisher, magazíne Zig-Zag, legitimation of literary production, "ciudad letrada".

* Este artículo constituye parte de los resultados de las tesis doctoral titulada "Revistas culturales y literarias chilenas de 1894 a 1920: Instancias legitimadoras para la autorización del campo literario nacional (PUCV, 2010). También forma parte de los resultados del Proyecto Semilla UCSH, en curso.

** Doctora en Literatura. Académica Universidad Católica Silva Henríquez. malvarado@ucsh.cl 


\section{Introducción}

En este trabajo nos interesa revisar cómo la editorial Zig-Zag, especialmente con su magazín homónimo, contribuyó en la producción literaria chilena y sus modificaciones, mediante qué estrategias de posicionamiento, consagración y canonización, y de qué modo logró reorganizar la serie de relatos ${ }^{1}$ culturales que se estaban produciendo en ese momento en el país. Según esto, consideramos que tanto la editorial como sus publicaciones se constituyeron en sí mismas en un metarrelato que pretendía abarcar la mayor cantidad de públicos lectores y que ordenara a la disgregada "masa lectora", inquieta por exponer y leer sus propios discursos. Por consiguiente, las revistas de Edwards (Zig-Zag y otras) fueron la respuesta discursiva burguesa ante la heterogeneidad sígnica y enunciativa predominante dentro de los veinte primeros años del siglo XX.

Para articular el trabajo, se revisa el impacto de la editorial y el magazín entre las publicaciones literarias y culturales preexistentes, distantes de la lógica editorial pero ricas en emergencia de discursos de productores autónomos, desvinculados de cualquier instancia de poder. Debido a la multiplicidad de sujetos opinantes, analizamos también las estrategias desplegadas por Zig-Zag, las que, lejos de ser un mero divertimento o instancias informativas para la masa lectora, intenta guiar o dar cuerpo a la opinión pública. En esta misma línea, la producción literaria también se encuentra supeditada a la línea editorial del magazín, razón por la que también problematizamos la supuesta autonomía que las escrituras de literatos/as alcanzan a lo largo de los primeros 15 años de la revista. Finalmente, para respaldar y argumentar nuestra crítica sobre la empresa editora y su emblemática publicación, nos concentramos en la función de la encuesta lectora que se organizó posterior a la celebración del Centenario.

\section{Zig- Zag y la irrupción editorial}

Intentar satisfacer la demanda de los lectores incorporando nuevos avances tecnológicos en el diseño e impresión de las revistas, es una importante señal que nos permite reconocer el nacimiento de la industria

1 Las nociones relato y metarrelato, para Lyotard (2006) hacen referencia a una misma idea, la cual apunta a que el saber, históricamente, se ha legitimado por medio de metarrelatos o relatos, los cuales junto con validar, otorgan peso a las instituciones que rigen el lazo social. De este modo, "la justicia se encuentra referida al gran relato, al mismo título que la verdad". (09) 
cultural moderna de la mano del formato magazín ${ }^{2}$, expresado total o parcialmente por las revistas de inicios de 1900 Pluma y Lápiz, La Lira Chilena, La Ilustración, Luz y Sombra, Instantáneas, Instantáneas de Luz y Sombra y La Juventud. Junto al incuestionable aporte y la contribución de estos periódicos en la autonomización del campo literario chileno y en la legitimación de escritores y escritoras, éstos demostraron la resignificación de los contenidos literarios y artísticos a través de modelos más dinámicos, donde ya no era prioridad presentar a los agentes que iban a encontrarse en la "arena literaria" ni demostrar un nuevo repertorio ${ }^{3}$ estético, ya que la preocupación estaba en reafirmar los nombres de los/las literatos/as y proclamarlos/as como consagrados/as. A esto se suma el interés por demarcar los círculos intelectuales instituidos tras las publicaciones, no sólo en términos de amistades y redes sociales, sino que como conjunto de profesionales especializados en la prensa cultural y literaria.

Dichas revistas, pese a adoptar parte del diseño magazinesco, se dedicaron exclusivamente a temas artísticos, literarios y culturales, generándoles un capital específico que les permitió diferenciarse de las demás manifestaciones escritas de la prensa del período. No obstante la renovación de las revistas, su público continuó siendo reducido a lectores más especializados y no por un público masivo pese al dinamismo de las nuevas gráficas incorporadas.

El Mercurio de Santiago supo aprovechar el cuerpo intelectual forjado al alero de los periódicos literarios preexistentes, agrupándolos en sus salas de redacción y sus columnas. Pero para Agustín Edwards Mc

2 El magazín es definido convencionalmente como, un periódico ilustrado [...] Se trata de un género que es capaz de albergar en su interior en forma entremezclada crónicas, entrevistas, reportajes de actualidad, ilustraciones, avisos publicitarios, cuentos y novelas por entrega, notas de vida social, caricaturas, poemas, etc. En este sentido, se trata de un género extraordinariamente maleable en cuanto a sus formatos y contenidos. (Ossandón, Santa Cruz, 2005, 33)

3 La noción de repertorio, la consideramos a partir de la teoría de los (Poli)sistemas de Itamar Even-Zohar, quien explica que "en el (poli)sistema, la canonicidad se manifiesta con mayor concreción en el repertorio. Mientras que el repertorio puede estar canonizado o no, el sistema al que pertenece un repertorio puede ser central o periférico" (1990, 18). El investigador israelí considera que todo fenómeno semiótico debe estudiarse desde una propuesta sistémica, donde las diferentes esferas de producción de bienes culturales no sean consideradas aisladamente, sino que en relación a las intersecciones e interferencias que se generan entre unas y otras, es por ello que a su teoría la denomina (poli)sistemas. En cuanto a la noción de repertorio, EvenZohar explica que en el (poli)sistema habita un conjunto de posibilidades, las cuales pueden ser centrales o marginales, a las que titula con dicho nombre. Las posibilidades efectivas de realización del repertorio central o periférico, lo denomina modelos, quienes pugnarán por derrocar a los modelos de los repertorios canónicos y, gracias a esta lucha, propiciar la movilidad del (poli)sistema. 
Clure el tabloide no era suficiente y creyó que éste necesitaba de un suplemento, aunque El Mercurio ya tenía bastante audiencia y se valía por sí mismo. De allí que en 1904 Edwards comenzara a proyectar lo que posteriormente sería Zig-Zag.

Esta inversión resultó inédita para la época, pues Agustín Edwards era conciente que a diferencia de otras transacciones económicas, los resultados y beneficios pecuniarios no serían inmediatos sino que a largo plazo. Pero involucrarse en este proyecto no sólo respondía a una intuición, pues los factores de la época indicaban que una empresa como esta sería bien recibida, idea que se infiere desde los comentarios de Félix López en el número conmemorativo de los cincuenta años de Zig-Zag:

En este florecimiento literario, cultural y artístico del 1900 y años inmediatos, figuran nombres y ahora ya consagrados y muchos de los cuales, para gloria del arte y las letras nacionales, aún perduran y producen bellas obras.

Naturalmente, estas figuras relevantes del arte y la literatura nacionales, así como sus seguidores y discípulos, que formaban legión, necesitaban de la prensa para expresar sus anhelos, sus ideales y sus ansias de renovación. Y es por eso que en esta época encontramos también un apreciable número de 'revistas' o publicaciones semanales, mensuales o quincenales que editadas en Santiago, Valparaíso y Concepción, interpretaban las diversas modalidades de cenáculos o capillas artísticas y literarias.

Con todo, el ambiente editorial estaba ya preparado por entonces para publicaciones de una mayor pretensión, con vistas a abarcar públicos más vastos, aunque en ellas fuera sólo una parte la expresión netamente literaria, dejando para el resto la nota periodística y de actualidad de los acontecimientos de la vida nacional y extranjera.

(Medio Siglo de Zig-Zag..., 1955, 65)

Zig- Zag absorbió a los escritores ya consagrados, provocando que las revistas de propiedad de escritores y no de editoriales desaparecieran. 


\section{La expansión de la "ciudad letrada" zigzagueante}

El magazín Zig-Zag junto a Selecta y las demás revistas de la misma casa editorial, se configuraron como la respuesta burguesa-empresarial frente a los múltiples discursos culturales, literarios, artísticos, sociales, políticos, informativos, entre otros, que en 1905 configuraban públicos lectores específicos.

A partir de los estudios de Ángel Rama (1998) y sus análisis sobre la mecánica de las sociedades latinoamericanas del siglo XIX desde la perspectiva cultural y social, extendemos sus clasificaciones para este estudio y para comprender los procesos de cambio que se generaron en la esfera de producción literaria. Siguiendo sus categorías, en este período inicial de siglo encontramos una "ciudad revolucionada", donde la casa editorial Zig-Zag antecedida por El Mercurio, intentaron ordenar y organizar esta multiplicación discursiva, la que más allá de ser peligrosa para el poder político rector, era una amenaza para los intereses económicos y los discursos hegemónicos de los ostentadores de dicho capital. De allí que propongamos que las publicaciones de la empresa de Edwards fueron la contra-jugada para absorber públicos y escritores (de la mayor cantidad de especialidades posible), y de este modo re dirigir a los lectores, so pretexto de "darles siempre en el gusto", y coartar-controlar a los literatos tras el subterfugio de darle en el gusto al público. Sobre esta organización, Rama explica

[que] Pareció posible que los intelectuales actuaran directamente sobre el público (y éste reactuara sobre ellos, imponiéndoles incluso una escritura y especiales formas) sin que esa comunicación fuera orientada y condicionada desde el poder, sean quienes fueran lo que lo ocupaban.

El estudio de las revistas de Zig-Zag desde las relaciones que indicamos, nos permite problematizar cada revista individualmente y las secciones del magazín, a la luz de las estrategias desplegadas para mantener esta doble estrategia que hemos señalado. Selecta, por ejemplo, significó

4 Selecta fue dirigida por Luis Orrego Luco, quien gracias a Casa Grande aparecida en 1908, incrementó generosamente su capital simbólico, pues fue reconocido como un novelista interesante, capaz de retratar los tipos humanos de la sociedad nacional, problematizarlos y analizar sus comportamientos y las causas de éstos, tal como si la novela fuera un laboratorio. Considerando lo anterior, Orrego tuvo mayores licencias para afinar sus crónicas en Zig-Zag, instalando en dichos textos asuntos tan contingentes y polémicos, como la presencia de mujeres en las letras y el posicionamiento de la labor del escritor como profesión y no como un oficio. 
un desprendimiento respecto del "juego" instaurado, el cual no funcionó pues no consiguió cautivar lectores suficientes para sostener la revista tanto en términos monetarios como en "ranking" lector. Según esto, las estrategias y disposiciones del magazín fueron efectivas y la corta existencia de la revista de Orrego le dio la razón a los procedimientos de Zig-Zag.

Esta expansión de la "ciudad letrada" no sólo abarcó temas culturales y literarios, sino también políticos y sociales, asuntos sobre los cuales representó una perspectiva sesgada, pese a los intentos por presentarla como amplia y democrática. En este sentido, según El Estallido de las formas, "una de las más importantes tareas que el magazín jugó (y sigue jugando) en los procesos de modernización dice relación con la divulgación y vulgarización del conocimiento" $(2005,35)$. No sólo se propagó información relativa a los avances tecnológicos del país, como lo hicieron las revistas de principios de 1900, sino también sobre las organizaciones de obreros, de mujeres, políticas y religiosas, con el objetivo de incorporar a la "vida social" de Zig-Zag a los sectores populares y/o emergentes.

No es riesgoso afirmar entonces, que la industria cultural tuvo incidencia en las transformaciones sociales, sobre todo en lo referente a esta democratización cultural o, como lo llamó la elite, a la vulgarización del "gusto", significación peyorativa que utilizaron para caracterizar a la prensa masiva dirigida a lectores menos instruidos. Junto con estas denominaciones despreciativas, Zig-Zag contraatacó con la resignificación del concepto de ilustrado, calificativo con el que definió a todas sus revistas.

Mientras que las revistas anteriores al magazín utilizaron el adjetivo "ilustrado" para referirse a los dibujos, láminas y retratos que contenían, Zig-Zag lo hizo para señalar a quienes tuviesen las características intelectivas adecuadas y a quienes fuesen ostentadores del capital simbólico que les permitiera participar de las esferas de poder. En este sentido, "ilustrado" se utilizó para hacer una distinción social más que intelectual. Ángel Rama en La ciudad letrada explica que aquellos medios periodísticos dirigidos al público culto o semi-culto intentaron resguardar la antigua "ciudad letrada", de allí que revistas como Zig-Zag se hicieran llamar ilustradas, así también las demás publicaciones de la misma casa editora.

Debido a las subdistinciones y discusiones que se generaron a partir de lo que era o no ilustrado, la empresa Zig-Zag se vio en la obligación 
de publicar dos nuevos magazines, uno ilustrado-popular, Corre-Vuela en 1908, y Pacífico Magazín en 1913 ilustrado de elite. Por ende, la pregunta que cabe es respecto al lugar en que quedó Zig-Zag acorde a esta nueva ordenación.

La revista emblemática, metafóricamente quedó en el medio, entre el magazín de elite y el popular. Pero este espacio intermedio tiene directa relación con el sector social sobre el cual se concentró: los crecientes sectores mesocráticos, los que hacia fines de la segunda década del XX ya estarían establecidos como clase media. Sobre este asunto da cuenta el artículo aparecido en el número 738 de la revista en el año 1919, titulado "Divagaciones sobre la clase media y la aristocracia":

Se está formando, o tratando de formarse, una Federación de la Clase Media, con fines de ayuda y defensa. Las últimas huelgas, el maximalismo, la organización de los gremios de obreros con sus Consejos Federales numerados, han puesto de relieve la necesidad de unir los intereses comunes y de ahí esta nueva Federación. Si llega a formarse, lógicamente le seguirá mañana alguna asociación de la clase alta, de la 'aristocracia' como dicen Juan Duval y las costureras y de la oligarquía como dice Tancredo Pinochet y ha seguido diciendo 'La Opinión', incluidos tal vez inconscientemente [...] Entonces tendríamos la sociedad moderna dividida en tres 'Estados' [...]

$$
\text { H.D.A. }
$$

$$
\text { (Zig-Zag, no 738, } 12 \text { de mayo, 1919, s/p) }
$$

El artículo de Hernán Díaz Arrieta problematiza las nuevas nomenclaturas sociales y los sectores que las ostentan, reseñando el contexto bajo el cual Arturo Alessandri Palma asumió la presidencia, el "León de Tarapacá", quien reunía las expectativas de la clase media. Muchas de esas organizaciones de trabajadores que Díaz Arrieta menciona fueron retratadas por Zig-Zag.

En definitiva, la empresa Zig-Zag y sus publicaciones protagonizaron el proceso de reorganización sociológica y cultural de la sociedad, como explica Ossandón (2005), "no es nuevo señalar que los procesos de modernización [...] implican la experiencia cotidiana de los individuos se traslada de los grupos primarios a los grupos de referencia secundarios" (37). Es así como se madura la opinión pública, sectorizada gracias al imaginario reforzado por las mismas publicaciones, modalizada a través de las encuestas organizadas por la misma y la recepción de cartas al 
director. Pero esta comunicación fluida con el público también resultó poco amena y un tanto exigente como cuenta el artículo aparecido el año 1915 en la revista titulado "Los caprichos de la opinión":

Sólo aquellos que han tenido a su cargo la dirección de un periódico pueden darse cuenta de lo que significan los sinsabores cotidianos de estarle mirando el rostro al público y adivinando en él las impresiones le produce el artículo cual o la gacetilla tal ¿Quién no se considera con derechos para reprochar todo lo que no se estima de su agrado en el diario o en la revista? [...]

(Zig-Zag, n 521, 13 de febrero, 1915)

\section{Trayectoria y ¿̨autonomización? de la producción literaria en $Z i g-Z a g$}

Zig-Zag se posicionó como el magazín por antonomasia entre la serie de publicaciones del período, inclusive entre las de su misma empresa editorial gracias a la heterogeneidad temática, la que abarcaba la mención y homenaje a festividades religiosas y civiles, tanto nacionales como extranjeras.

La conmemoración de la Semana Santa, el nombramiento de un nuevo Arzobispo de Santiago, la cercanía de la Fiestas Patrias o el homenaje a países como Francia y Estados Unidos con ocasión de la celebración de sus respectivos días de la Independencia, no sólo implicaban la mención en la portada de la revista o algunos reportajes dentro de esta sobre el mismo asunto, sino que Zig-Zag se destinaba íntegramente para resaltar el hecho. Es así como si se trataba de Navidad, por ejemplo, desde los reportajes, la sección de vida social, de cocina, de modas, la producción literaria inserta en ese número, entre otras, estaban dedicadas al 25 de diciembre.

Este tipo de circunstancias, según se ha mencionado, generaban un "recorte" sustancioso por parte de los editores del magazín, pues para el caso de los textos literarios, del género que fueran, debían tratar sobre el tema central del número. Un ejemplo, es que la revista 60 del 8 de abril de 1906, la cual versaba sobre La Semana Santa, aparecieron los textos "Los Pescadores", de Federico Gana y "Hacia el Oriente" de Inés Echeverría. Esta situación se reiteró con las demás circunstancias evocadas en el magazín, lo que nos permite corroborar con mayores antecedentes la falta de autonomía de las producciones literarias aparecidas en ella 
debido a las diversas condiciones que debían sortear. En primer lugar, ser convocado de manera personal luego, atender a los requisitos de los editores, y posterior a la entrega del material, esperar ser seleccionado.

Si bien esta modalidad restó espontaneidad productiva a los escritores y escritoras de la época, nos permite afirmar que el campo literario ya se encontraba bastante más organizado, pues esas exigencias y etapas de prueba que la producción debía aprobar, responde a la presencia de instancias legitimadoras capaces de valorar positiva o negativamente el material de los productores. Respecto a éstos últimos, para conseguir ser publicado, para lograr guiarse por las reglas impuestas y que junto con ello el resultado fuera óptimo, debían tener cierta especialización que les permitiera conjugar elementos, normativos y creativos. Por lo tanto, este "juego" de Zig-Zag fue un aporte para la autonomización del campo, pues demarcó la vereda incumbente y sus respectivos criterios de validación.

Pero si nos centramos en la presentación de textos literarios dentro de la revista, es inadecuado pensar en una sección literaria, por lo menos hasta el año 1914, donde la dispersión de cuentos, poemas, crónicas y entrevistas disminuyó sustanciosamente y se comenzaron a probar formas para organizar de un modo más compacto dicho material.

Para establecer una suerte de periodización sobre los cambios que la presentación del contenido escritural sufrió, tenemos que considerar un primer momento, desde 1905 a 1908, donde no eran más de dos los cuentos o poemas de escritores nacionales, frente a dos o más de extranjeros como Zolá y Tolstoi. Respecto al repertorio literario desarrollado a través de la producción publicada en estos primeros años, ésta adhirió al criollismo, afirmación argumentada en base de la convocatoria del primer Certamen Literario de Zig-Zag de 1907, cuya presentación fue la siguiente:

\section{Certamen Literario de Zig-Zag}

La administración de Zig-Zag ha resuelto abrir para el número especial del 18 de septiembre un certamen literario, con las siguientes bases:

Habrá cuatro temas:

Primer tema.- Cuento histórico o de costumbres nacionales, concerniente a la época de la Independencia.

Segundo tema.-Semblanza de alguno de los personajes que figuraron en el 18 de septiembre de 1810.

Tercer tema.-Origen de la bandera nacional. 
Cuarto tema.-Apreciaciones acerca de cuál de las acciones de guerra de la Independencia tuvo mayor mérito militar.

$$
\text { (Zig-Zag, no 129, } 11 \text { de agosto, 1907, s/p) }
$$

Según la fecha del concurso, un mes antes de la celebración del 18 de septiembre, se entiende la razón en la selección de los temas que se propusieron, la que no se debió a cuestiones conservadoras, a la usanza del 1800 y la propugnación del metarrelato histórico, sino que así como pudo tratar sobre asuntos nacionalistas, también pudo haber sido sobre temas religiosos $\mathrm{u}$ otros festejos civiles teniendo en consideración el período del año. Esto demuestra que las diferentes instancias institucionalizadoras, así como el concurso y la crítica, no sólo estaban al servicio del campo literario completo, sino que a las reglas editoriales de la revista.

En el año 1909, lo poco que se publicaba de literatura nacional quedó prácticamente en cero, siendo ocupados los espacios vacantes por las nuevas secciones, la de cocina, hogar y asuntos estéticos ligados al bienestar y la belleza femenina, firmadas por Catalina y Lorani. Consideramos que esta merma se debió a que en ese año apareció Selecta, la que estaba dedicada íntegramente a asuntos literarios, como ya hemos indicado, por lo que los colaboradores literarios se concentraron en la revista de Orrego Luco. Este período de escasez se extendió hasta 1913, un año después del cese de la revista dirigida por el autor de Casa Grande, donde se empezaron a publicar las "Entrevistas Literarias" realizadas por el poeta Daniel de la Vega a escritores y críticos reconocidos, como Emilio Vaïsse, Joaquín Díaz Garcés, Agustín Barriga, Miguel Luis Rocuant, Manuel Magallanes Moure, Armando Donoso, Fernando Santiván, Carlos Mondaca, Max Jara, Nathanael Yáñez Silva, entre otros.

De todos modos, no podemos omitir dos grandes aportes que entre los años que hemos señalado, 1909 y 1913, Zig-Zag desplegó, los cuales significaron auténticas performances ${ }^{5}$ para el posicionamiento y cohesión del conjunto de colaboradores del magazín. En primer lugar, en el número 208 de 1909, se publicó un fotorreportaje con los colaboradores literarios del magazín. Este acto de reconocimiento fue sucedido en el año 1910, en los números 262, 264 y 266, con la publicación de los

5 Para Lyotard (2006), los lazos sociales y los juegos que se generan a partir de ellos, están mediatizados por la fuerza de los juegos discursivos que se despliegan. A los enunciados que tienen la característica de buscar y lograr un efecto sobre el referente, los denomina performativos. Junto a lo anterior, señala además que quien pronuncia o articula esta clase de enunciados, debe estar dotado de autoridad, para hacer más efectiva la respuesta por parte del interlocutor. 
listados de los nombres de los escritores y escritoras con sus respectivos seudónimos.

Respecto de lo último, más allá de satisfacer a los lectores, quienes en la sección de cartas y preguntas frecuentes solicitaban continuamente el develamiento de las verdaderas identidades de los y las literatos y literatas, este descubrimiento responde a otra de las estrategias de la revista. El uso de seudónimos genera un fascinamiento tanto a los que los adoptan, pues les otorga una nueva personalidad escritural, como a quienes leen a autores y autoras que se ocultan tras ese enmascaramiento discursivo, pues está la permanente pregunta sobre quién será el/la "disfrazado/a". Esto último es lo que Gerard Genette (2001) reconoce como el "efecto seudónimo", pues el lector sabe que se trata de un seudónimo el nombre que figura como autor de tal o cual obra, pero no sabe la identidad original de éste.

Cuando Zig- Zag revela dicha información, más allá de provocar que el público deje de especular gracias al paratexto que expone, lo que consigue a través del reconocimiento del nombre "legal" es, según Genette, "ningún escritor que usa seudónimo puede soñar con la gloria sin prever esta revelación" (46), pues si su patronímico es publicado, significa que es lo suficientemente importante o interesante como para entregar una biografía o semblanza respecto de éste. Por lo tanto, este (des)cubrimiento hecho por Zig-Zag, es parte de las herramientas de consagración de sus propios colaboradores, elemento también crucial dentro del proceso de autonomización del campo literario.

Un tercer momento interesante para la producción literaria dentro del magazín nacional, es la que se suscita entre los años 1914 en adelante. A partir de esa fecha se evidencia una mayor especialización y profundización sobre los asuntos relativos a la producción literaria nacional y Latinoamericana. Un factor clave para ello fue la celebración de los Juegos Florales ${ }^{6}$ del '14, certamen que fue ganado por Gabriela Mistral con "Los Sonetos de la Muerte". Junto con la relevancia de este concurso debido a que la triunfadora fue una poeta, dicho evento demostró que en Chile existía un circuito importante de escritores y escritoras, interesados en renovar el repertorio literario, y complejizar la producción artística no sólo gracias a la originalidad de sus trabajos sino también a

6 Fueron organizados por la Sociedad de Escritores y Artistas, durante los cuales un jurado compuesto por el crítico literario Armando Donoso, el poeta Manuel Magallanes Moure y el escritor Miguel Rocuant eligió, entre las obras presentadas, las siguientes: "Los Sonetos de la Muerte", de Gabriela; "Plegaria a María", de Julio Munizaga Ossandón; "Rogativas a mi corazón", de Pedro Sienna; "Salomé", de David E. Bari, y "Psalmo al amor", de Claudio de Alas. 
los inéditos habitus ${ }^{\top}$ con los que cada uno/a comenzó a pugnar espacios para ingresar al campo.

Ese hito provocó un incremento en las colaboraciones literarias publicadas por la revista, aunque ello no implicó que si el magazín estaba dedicado a algún evento religioso, político y social, el material literario se zafara de ser parte del gran homenaje. No obstante ello, Zig-Zag se implicó en la actualidad literaria, creó secciones como "Chismografía literaria" donde polemizó con Vicente Huidobro y otros escritores, aunque el avance más interesante, fue la creación del suplemento inserto en el magazín llamado "Pórtico Literario", aparecido por primera vez en el número 611 del año 1916. Dentro de este anexo, los escritores como Iris, Roxane, Shade, Magda Suderman, Winétt de Rokha, María Monvel, el mismo Huidobro y los demás literatos del período, se hicieron partícipes activos. El "Pórtico" no sólo estaba delimitado por las portadas que lo encabezaban, sino también por el tipo del papel del cual estaba manufacturado (cuché brillante) diferente del resto de la revista (cuché mate).

Junto a lo anterior, Zig-Zag incluyó en el último mes del año balances de la producción literaria, a la vez que periódicamente procuró dar a conocer los libros nuevos y mayor cantidad de artículos sobre crítica literaria. A esto se sumó la encuesta literaria, de la cual también nos ocuparemos.

Hacia 1920, la empresa Zig-Zag publicaba libros de escritores chilenos que colaboraban en ella acentuando aún más su promoción mediante las reseñas o la presentación de extractos de las producciones para atraer al público lector. Por otra parte, la obligatoriedad temática sobre los textos literarios acorde a las fechas conmemorativas, disminuyó sustancialmente ya pasado 1916, pues el mismo "Pórtico Literario" quedaba ajeno a los homenajes, limitándose a asuntos netamente artísticos. En definitiva, podemos afirmar que la producción literaria encontró en este magazín en los dos primeros decenios del siglo XX un espacio legitimador importante, el que si bien estaba bastante controlado durante los primeros diez años, la presión ejercida por los agentes que buscaban renovar el repertorio permitió dinamizarlo y actualizarlo acorde a las necesidades de los escritores y escritoras.

7 La noción de habitus la consideramos a partir de la conceptualización dada por Pierre Bourdieu, quien la explica como "sistemas de disposiciones que, al ser producto de una trayectoria social y de una posición dentro del campo literario, encuentran en esa posición una ocasión más o menos propicia para actualizarse (la construcción del campo es lo previo lógico a la construcción de la trayectoria social como serie de posiciones ocupadas sucesivamente en este campo)"(2005, 318). 


\section{La encuesta o la "democracia" lectora}

Con fecha 2 de septiembre del año 1916, en el número 602 de la revista, apareció por primera vez en Zig-Zag la "Encuesta Literaria", creada a partir del impulso que dio a los editores del magazín el interés de los lectores por opinar respecto de los escritores y escritoras que hacia ese año aparecían en la revista. Las preguntas y comentarios del público eran recepcionados como cartas al director, las que eran citadas en el apartado "Preguntas y Respuestas". La presentación oficial de esta nueva sección manifestó las siguientes ideas:

\section{ENCUESTA LITERARIA \\ ¿Cuáles son sus autores predilectos?}

En nuestro número pasado publicamos varias respuestas a la pregunta que encabeza estas líneas: ¿Cuáles son sus autores predilectos?...

'Zig-Zag' trata de inquirir gustos literarios de sus entrevistados. Opiniones de mentalidades, preparadas en constante ejercicio intelectual, pueden servir de índice a nuestros lectores y de tema para apreciaciones muy diversas. Toda encuesta está encaminada a señalar rumbos...ya en el orden político, social o estético.

En literatura hay escuelas de diversos colores; campos de acción opuestos los unos de los otros y en los que descuellan grandes figuras aureoladas por el prestigio de las admiraciones universales [...]

(Zig-Zag, no 602, 02 de septiembre, 1916, s/p)

Nos interesa revisar esta sección en particular, no sólo porque se extendió hasta el mes de mayo del año 1918, sino también por su propósito, el cual se enuncia en la cita y, particularmente, el enunciado ennegrecido, donde se señala el interés por intervenir y guiar las opiniones del público. Por lo tanto, mediante la encuesta esta revista introdujo otra estrategia para modelar los gustos de los lectores enmascarada tras la pretensión de democratizar los privilegios textuales.

Dentro del texto citado, por otra parte, se instalan las "reglas" a partir de las cuales este nuevo "juego" literario, social y cultural se estructuró. Según se observa, hace alusión al capital cultural de quienes participen con sus votos, "opiniones de mentalidades, preparadas en constante ejercicio intelectual". Pierre Bourdieu en el capítulo "El misterio del

8 El ennegrecido y subrayado es nuestro. 
ministerio. De las voluntases particulares a la "voluntad general"' (2005) aparecido en el libro El Misterio del Ministerio, aborda justamente esta falsa equidad propuesta por toda clase de procesos sufragistas. Por lo mismo, la lectura escéptica respecto de estos asuntos es particularmente evidenciable en el caso que estudiamos, donde junto con intentar manipular a los lectores, subyace el discurso consagratorio que intenta "hacer creer" a los lectores que quienes han legitimado a tal o cual escritor han sido ellos y no agentes de poder ajenos a la misma producción literaria. ${ }^{9}$

Los procedimientos del magazín para dar cuenta de los votos obtenidos por los poetas partícipes del litigio, donde se encuentran Gabriela Mistral, Daniel de la Vega, Víctor Domingo Silva, Pedro Antonio González, Jorge Hübner, Manuel Magallanes Moure, Pedro Sienna, Antonio Bórquez, Alberto Mauret Caamaño, entre otros, no sólo incluía el listado de votos con su respectiva cantidad, sino también a las personas que habían emitido esos votos. Por lo tanto, tampoco se trató de una encuesta anónima, por el contrario, dar a conocer las personalidades que se hacían presentes de este evento era parte del acto de legitimación y posicionamiento tanto del sufragista como de su beneficiado.

En cuanto a los escritores y la escritora participantes de esta "competencia” pública, todos ellos eran colaboradores del magazín, por lo que no figuran poetas como Vicente Huidobro o Pablo de Rokha, quienes para los años de organización del certamen ya formaban parte del campo literario, pero del sector de los contendientes que estaban pugnando posiciones con nuevas propuestas estéticas y proyectos culturales más arrojados. Por ende, con este último antecedente se reafirma la falta de democracia en la justa de Zig-Zag, la que pese al despliegue, la promoción y los casi dos años a través de los cuales se sostuvo, esta no dejó de generar polémicas, justamente por lo que planteábamos arriba, el privilegio de unos poetas por sobre otros. El intento por esclarecer la discusión que se entabló en periódicos que tomaron con seriedad el concurso, motivó la publicación de un comunicado público de parte de la Dirección de la revista:

9 Por otra parte, respecto del capital específico que se le exige a los votantes, nos interesa revisar lo que expone el sociólogo, [...] la lógica del voto, que normalmente se tiene por paradigmáticamente democrática, sea doblemente desfavorable para los dominados: de una parte, no todos los agentes poseen en el mismo grado los instrumentos, especialmente el capital cultural, que son necesarios para producir una opinión personal, en el doble sentido de autónoma y conforme a la particularidad de los intereses vinculados a una posición particular (lo que significa que el voto no será el sufragio universal que pretende ser mientras no se universalicen las condiciones de acceso a lo universal) [...] (Bourdieu, 2005, 75) 


\section{LA SERIEDAD DE NUESTRA ENCUESTA}

Jamás hemos recurrido a testimonio ajeno para que nuestra palabra sea creída, así como nunca hemos necesitado pruebas para testimoniar la corrección de nuestros procedimientos.

Y esto se debe a que hasta hoy nadie ha puesto en tela de juicio lo que hemos hecho o lo que hemos afirmado.

Pero, con motivo de llevar la primera mayoría en la encuesta sobre los poetas chilenos, don Daniel de la Vega, empleado de esta revista, han creído algunas personas suspicaces (de la suspicacia a la malevolencia no hay sino un paso) que por compañerismo se ha alterado los cupones y votos a favor de De la Vega.

Creído algunas personas suspicaces (de la suspicacia a la malevolencia no hay sino un paso) que por compañerismo se ha alterado los cupones y votos a favor de De la Vega para obtener de éste gratitud o una mayor amistad.

Así, pues, en los diarios de provincias, se han descargado aquellos que en un principio de ilusionaron con la idea de ser los primeros, estallando su ira mal reprimida contra nosotros, por creer falta de seriedad o abuso al hacer escrutinio de los votos.

Varias veces nos ha tocado que poetas presenciaran nuestra labor y Víctor D. Silva, Jorge Hübner, Juan Guzmán Cruchaga y Ángel Cruchaga, entre otros, han visto cómo hemos llevado esta encuesta, y por sus propios ojos se han convencido de la mayoría que De la Vega obtiene diariamente. [...]

Comprendemos que muchos periodistas hayan sido engañados. La palabra convincente de que se han valido esos pelafustanes, animada por la envidia y el despecho, han podido engañar. Pero hoy podemos presentar nuestras pruebas, que ellas valgan por sí solas, ya que la seriedad de esta Empresa y el correcto proceder nuestro de nada ha valido para ellos.

Se nos ha acusado también de no publicar todos los juicios. En realidad los que han hecho tal afirmación son sólo personas vehementes que no han sido capaces de esperar algunos días para ver su nombre o pseudónimo en las so de cartas que diariamente recibimos y que publicamos en las páginas de nuestro semanario. Y la demora se debe única y exclusivamente al número inmenso de cartas que hace imposible publicarlas inmediatamente $[\ldots]$

LA DIRECCIÓN

(Zig-Zag, no 676, 02 de febrero, 1918, s/p) 
Zig-Zag procuró marginarse de discusiones directas emergidas desde los sectores autónomos de la prensa literaria, particularmente de las revistas aparecidas después de 1912. Las respuestas a las provocaciones de estas no pasaron de ser un "chiste" o la dedicatoria, solapada de poemas cargados de ironía. Pero al contrario de esas situaciones, con lo sucedido con la encuesta la historia fue distinta, pues los redactores no escatimaron en insultar y ridiculizar a quienes manifestaron su desconfianza respecto de esta encuesta y los procedimientos de la misma para validar al vencedor. No obstante ello, la poca probidad del proceso de elección del escritor favorito del público se evidencia a partir de la declaración que en el mismo texto se hace respecto de los ministros de fe, quienes "varias veces" presenciaron el conteo de votos, pero no siempre.

El ingreso del magazín en una polémica, en otro aspecto, aseguraba su vigencia dentro del dinámico campo literario de la época, pues quien no participara de las pugnas por las posiciones y por legitimarse, simplemente quedaría excluido y desactualizado. Por ende, esta es una estrategia tanto de la publicación como de los colaboradores que son parte de ella para mantenerse en la palestra. En este sentido, en el texto se enuncia que la institución que legitima tanto a la revista como a sus diferentes instancias es una "empresa seria", lo cual la posiciona en el lugar de una producción heterónoma, apoyada por el campo de poder y el grupo dominador del campo literario y cultural.

Luego de la disputa generada a raíz de la encuesta, se entregaron los resultados nueve números después, donde previo a exponer el listado, se publicó un nuevo comunicado en el que nuevamente se argumentaba a favor de la seriedad del concurso y del adverso clima en el que ésta se desenvolvió, aunque pese a ello resultó exitosa y representativa de los "buenos lectores",

\section{Nuestra encuesta de los poetas}

Damos fin hoy a la Encuesta Popular sobre cuál es el poeta chileno predilecto. Podemos decir, sin temor de pecado de fatuidad, que hemos tenido un éxito franco y verdadero. Aproximadamente 4 mil lectores han dado respuesta a la pregunta que hemos dirigido. Y justo es decir que salvo raras excepciones, siempre las respuestas han sido serias y bien puestas. La encuesta de Zig-Zag levantó un torbellino. Se nos acusó de adulterar votos a favor de un determinado poeta. Fuimos entonces donde un notario, que comprobara con su palabra oficial, la corrección de nuestros procedimientos, los que fueron ampliamente justificados. 
Daniel de la Vega ha triunfado con una mayoría cierta, vigorosa. De la Vega el poeta sentimental y magnífico, es el predilecto de nuestro público. [...]

Víctor Domingo Silva, el poeta vigoroso, de inspiración robusta y rima segura, ha obtenido el segundo puesto. El público en un principio ha librado ruda batalla en su espíritu, hasta llegar a emitir su opinión. [...]

Nuestra labor, pues, ha terminado. Hemos dado a conocer el juicio popular sobre nuestros poetas. Sólo hemos perseguido lograr interesar a la gran masa del público, en la poesía y en el arte nacional. Hemos recibido desilusiones, ataques, improperios. Pero nada nos ha detenido. Íbamos tras un ideal que hemos conseguido. Deseábamos sondear la opinión popular y lo hemos logrado. Ese ha sido el fin que nos ha servido en la presente encuesta. [...]

(Zig-Zag, no 685, 06 de abril, 1918, s/p)

Mientras que en las primeras publicaciones de Zig-Zag se abogó por la ausencia de novelistas frente al exceso de poetas, en 1918 la encuesta puso de relieve justamente a los poetas, contra quienes instauraron un discurso que destacaba su desorden, falta de disciplina y la vida bohemia que llevaban. Este "juego" democrático fue la contrajugada del magazín para detener la potencia que las revistas y los productores autónomos estaban alcanzando hacia 1920, quienes luego de experimentar la hegemonía de esta empresa editorial, retomaron proyectos individuales y grupales para superponer asuntos netamente literarios sobre preocupaciones comerciales.

\section{Observaciones de cierre}

A partir del análisis de Ángel Rama respecto a la "ciudad letrada" y sus reflexiones sobre la repartición de bienes culturales y el acceso a los mismos en las sociedades latinoamericanas, problematizamos la importancia de la editorial Zig-Zag y sus revistas, concentrándonos en su magazín homónimo. Mediante la lectura de los primeros quince años del semanario, aislamos los temas contenidos dentro éste para revisar la importancia de la publicación en la complejización de la esfera de producción literaria chilena.

La participación de escritores y escritoras en Zig-Zag, se constituye en un asunto crucial para comprender el proceso de autonomización del campo literario debido a los relatos que estas revistas posicionaron 
en los centros de discusión, como lo fue la instalación del criollismo como repertorio central de la primera década del siglo XX, el mayor capital simbólico de novelistas y cuentistas en desmedro de los poetas, la inclusión de la opinión pública dentro de las líneas editoriales y el manejo de esta por parte de los editores. Así también la aparición de las escritoras y, lo más interesante, los juegos y cruces discursivos generados entre el magazín y el conjunto de productores y publicaciones periódicas de la época.

A lo anterior se suma el elemento más destacable que a lo largo de este trabajo revisamos e intentamos corroborar, la rearticulación de la opinión pública por medio de estrategias de lectura y diversión a través de una publicación cuyo objetivo, lejos de ser meramente programático, responde a intereses editoriales hermanados o consecuentes con las instituciones constituyentes del campo de poder. De allí entonces que pusiéramos de relieve la línea editorial que regía la presentación de producciones literarias y sus criterios de selección y la organización de una encuesta dedicada a sondear las percepciones y guiar comentarios sobre la misma materia.

Por último, este artículo no ha pretendido cerrar el problema y otros más, muy por el contrario, deja abiertos espacios y preguntas que en próximos trabajos se procurarán abordar.

\section{Bibliografía}

\section{Bibliografía primaria}

ZIG-ZAG, Semanario Ilustrado. Santiago de Chile: Editorial Zig-Zag, Sociedad, Imprenta y Litografía Universo (SILUV).

(1907, 11 de agosto), núm. 129.

(1915, 13 de febrero), núm. 521

(1916, 2 de septiembre), núm. 602.

(1918, 2 de febrero), núm. 676.

(1918, 6 de abril), núm. 685.

(1919, 12 de abril), núm. 738. 


\section{Bibliografía crítica}

Bourdieu, P. (2002). Campo de poder, campo intelectual. Itinerario de un concepto. Buenos Aires: Montressor.

. (2005). Las reglas del arte. Génesis y estructura del campo literario. Barcelona: Anagrama.

Even-Zohar, I. (1990), Polysystem Theory. Esta versión es la traducción de "Polysystem Theory", Poetics Today 11, 9-26.

(1999). Factores y dependencias en la Cultura .Una Revisión de la Teoría de los Polisistemas". En Montserrat Iglesias Santos (comp.) Teoría de los Polisistemas: Estudio introductorio, compilación de textos y bibliografía. Madrid: Arco. (23-52).

Genette, G. (2001). Umbrales. México D.F.: Siglo XXI.

Lyotard, J.F. (2006). La condición postmoderna. Madrid: Cátedra.

Ossandón, C. y Santa Cruz, E. (2001). Entre las alas y el plomo. La gestación de la prensa moderna en Chile. Santiago de Chile: Lom.

. (2005). El estallido de las formas. Chile en los albores de la "cultura de masas". Santiago de Chile: Lom.

Rama, A. (1998). La ciudad letrada. Montevideo: Arca.

Wacquant, L. (coord.) (2005). El misterio del ministerio. Pierre Bourdieu y la politica democrática. Barcelona: Gedisa.e 